\title{
Preparation and Characterization of Cerium Doped Titanium Dioxide Nano Powder for Photocatalyst
}

\author{
Euphracia Ndinda, Hyun Park and Kyung Nam Kim ${ }^{\dagger}$ \\ Department of Advanced Materials Engineering, Kangwon National University, Gangwon 245-711, Korea
}

(Received November 11, 2013 : Received in revised form December 3, 2013 : Accepted December 10, 2013)

\begin{abstract}
This study was aimed at synthesizing and characterizing cerium-doped titania. Cerium-doped anatase titania powders were prepared by sol-gel process, with ammonium (IV) nitrate and titanium (IV) butoxide as the raw materials. The characteristics of pure $\mathrm{TiO}_{2}$ and cerium-doped $\mathrm{TiO}_{2}$ were investigated by XRD, TG/DTA, FE-SEM, and UV-vis spectroscopy. The results of this study show that anatase type of $\mathrm{TiO}_{2}$ was obtained in as-prepared and calcined $\mathrm{TiO}_{2}$ and $\mathrm{Ce}-\mathrm{TiO}_{2}$ powder. A DTA curve was also observed as the crystallization temperature decreased with increasing cerium contents. We found that the crystallite size of the obtained anatase particles decreased from $55 \mathrm{~nm}$ to $25 \mathrm{~nm}$ and the particle size decreased with increasing cerium contents. Moreover, UV-vis spectra showed that anatase titania powders with various cerium contents effectively extend the light absorption properties to the visible region.
\end{abstract}

Key words cerium, TBT, sol-gel process, anatase titania, photocatalyst.

\section{Introduction}

The development of nanocrystalline photocatalytic materials is rapidly a growing field of science and technology. This fact relates to the unique physical and chemical properties of $\mathrm{TiO}_{2}$. $\mathrm{TiO}_{2}$ bears tremendous hope in tackling the environmental issues we are currently facing. $\mathrm{TiO}_{2}$ is regarded as the most efficient material and environmentally begins photocatalyst: it has a wide range of potential applications and specially its materials exhibit photocatalytic activities. One drawback is unmodified $\mathrm{TiO}_{2}$ photocatalyst that works only with energies to operate in the UV wavelength $(380 \mathrm{~nm}, 3.2 \mathrm{eV})$ range and below which is the required energy wavelength to excite normal $\mathrm{TiO}_{2}{ }^{\left.1{ }^{1,2}\right)}$ This range is well below visible wavelength, which limits its indoor use or using effectively solar energy. ${ }^{3-5)}$ In addition, these materials may also exhibit photocatalytically induced super hydrophilicity that converts the hydrophobic character of the surface to hydrophilic when exposed to UV light. This causes the formation of uniform water films on the surface of these materials, which prevent the adhesion of inorganic or organic compounds and thus retain a clean surface on the photocatalyst. ${ }^{6}$ ) Hence these photocatalytic materials may be deployed on surfaces of various substrates such as glass, ceramics or metals to provide layers that exhibit self sterilization and self cleaning properties. ${ }^{7,8)}$

For effective utilization of solar energy, development efforts towards enlarging the absorption scope of $\mathrm{TiO}_{2}$ emerge as an appealing challenge. ${ }^{9,10}$ Therefore, the development of a new generation of photocatalyst is very important. There are many methods for preparation of visible light responsive photocatalyst such as doping of titania with metals and non metals. ${ }^{4,10,11)}$ Recently, doping $\mathrm{TiO}_{2}$ with rare earth ions has also attracted much attention. Doping the impurity ion is known as one of the most effective ways to manipulate the internal properties of host material such as crystallite size and the crystalline structure. $^{12,13)}$ The sol-gel route ${ }^{14,15)}$ has been developed in our laboratory for elaboration of $\mathrm{TiO}_{2}$ and properties of sol-gel derived $\mathrm{TiO}_{2}$ materials have been reported recently. ${ }^{16)}$ Therefore, Cerium doping $\mathrm{TiO}_{2}$ introduces a new energy level into the band gap of nano $\mathrm{TiO}_{2}$ making it possible to utilize light with a wavelength over $380 \mathrm{~nm}$ (visible light).

In this study, pure $\mathrm{TiO}_{2}$ and cerium doped $\mathrm{TiO}_{2}$ were prepared by sol-gel method. The presence of cerium ions in the titania matrix caused a significant absorption shift

\footnotetext{
${ }^{\dagger}$ Corresponding author

E-Mail : knkim@kangwon.ac.kr (K. N. Kim, Kangwon Univ.)
}

(C) Materials Research Society of Korea, All rights reserved.

This is an Open-Access article distributed under the terms of the Creative Commons Attribution Non-Commercial License (http://creativecommons.org/licenses/by-nc/3.0) which permits unrestricted non-commercial use, distribution, and reproduction in any medium, provided the original work is properly cited. 
to the visible region compared to the pure $\mathrm{TiO}_{2}$.

\section{Experimental procedure}

The following commercial reagents were used without further purification. Titanium (IV) butoxide (97\%, Sigma Aldrich) was used as precursor for synthesizing $\mathrm{TiO}_{2}$ particles. Ethyl alcohol (99.9\%, Ducksan reagents) was used as a solvent, Acetic acid, (99.5\%, Samchun chemical) was used as the catalyst. Ammonium cerium (IV) nitrate ( $98 \%$, Sigma Aldrich) was used as the source of cerium for doping $\mathrm{TiO}_{2}$. Distilled water was used in all of these experiments. We reported previously using the sol-gel process ${ }^{16)}$, pure $\mathrm{TiO}_{2}$ and $\mathrm{Ce}-\mathrm{TiO}_{2}$ synthesized with various Ce contents.

A series of $\mathrm{TiO}_{2}$ and $\mathrm{Ce}-\mathrm{TiO}_{2}$ samples were prepared according to the following procedures: 1 mole of TBT (97\%, Aldrich) diluted with $25 \mathrm{ml} \mathrm{C}_{2} \mathrm{H}_{5} \mathrm{OH}$ was added in drop, vigorously stirring into $80 \mathrm{ml}$ distilled water. The solution was stirred for 45 minutes at $70{ }^{\circ} \mathrm{C}$, and then 3 $\mathrm{ml} \mathrm{CH}_{3} \mathrm{COOH}$ was added in drops. The resulting solution was continuously stirred for 1 hour at $70{ }^{\circ} \mathrm{C}$. A clear sol was obtained and aged for 12 hours at room temperature to obtain gel. The gel was dried at $70{ }^{\circ} \mathrm{C}$ for 5 hours and then calcined at $550{ }^{\circ} \mathrm{C}$ for 2 hours to obtain anatase $\mathrm{TiO}_{2}$. Cerium doped titania was prepared similarly to pure titania: solution containing 1 mole of TBT, $25 \mathrm{ml}$ $\mathrm{C}_{2} \mathrm{H}_{5} \mathrm{OH}$, and $80 \mathrm{ml} \mathrm{H}_{2} \mathrm{O}$ was prepared and solution containing $3 \mathrm{ml} \mathrm{CH}{ }_{3} \mathrm{COOH}, 10 \mathrm{ml} \mathrm{C}{ }_{2} \mathrm{H}_{5} \mathrm{OH}, 10 \mathrm{ml} \mathrm{H} \mathrm{H}_{2} \mathrm{O}$ and Ammonium cerium (IV) nitrate, was added in drops, vigorously stirring. The subsequent characterization procedure was as mentioned below.

Crystalline phases of the as-prepared samples were revealed by powder X-ray diffraction(D/Max-2200, Rigaku, Japan). The microstructure of the powders were observed with FE-SEM(JSM-6701F, Japan). The thermal behavior of the dried gel was investigated using TG-DTA(STA 409 , Netzsch, Germany), and carried out at up to $800{ }^{\circ} \mathrm{C}$ in air at a constant heating rate of $5{ }^{\circ} \mathrm{C} / \mathrm{min}$ using $\mathrm{Al}_{2} \mathrm{O}_{3}$ as the reference material. UV-vis spectrometer(V-550, JASCO, Japan) showed the wavelength of the powders.

\section{Results and Discussion}

The XRD patterns of $\mathrm{TiO}_{2}$ and $\mathrm{Ce}-\mathrm{TiO}_{2}$ are shown in Fig. 1. In all samples, to be pure anatase phase, the most intense diffraction at $2 \theta=25^{\circ}$ is assigned to anatase $\left(\mathrm{d}_{101}\right)$. The powders showed the crystalline pattern and the observed d-lines matched the reported values for anatase phase. A single-phase anatase type of structure was detected for the cerium doped samples, and no trace of cerium diffraction peaks. Upon calcinations, the intensity of diffraction peaks is broader and weaker compared to

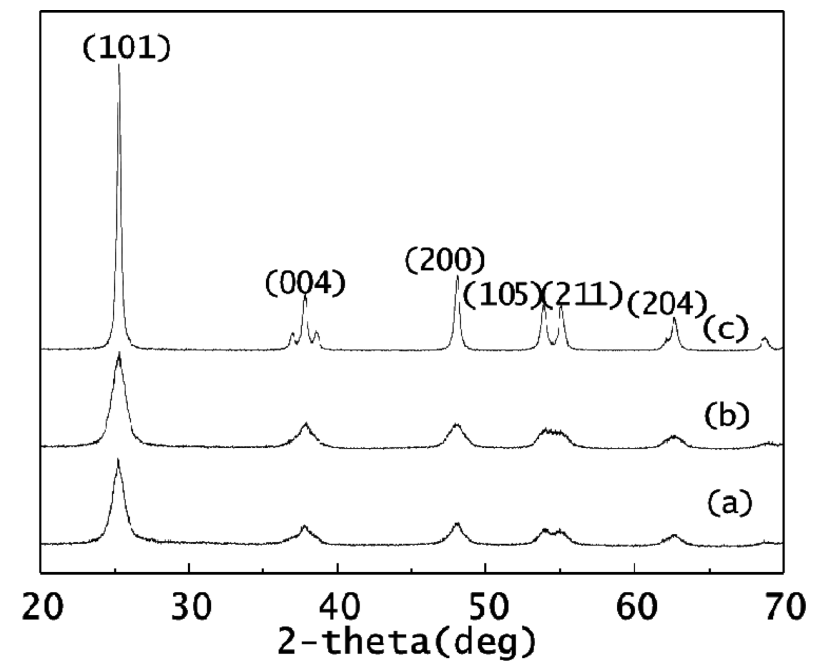

Fig. 1. X-ray diffraction patterns of (a) $0.44 \mathrm{wt} \% \mathrm{Ce}-\mathrm{TiO}_{2}$, (b) $0.09 \mathrm{wt} \% \mathrm{Ce}-\mathrm{TiO}_{2}$, and (c) $\mathrm{TiO}_{2}$ powder calcined at $550{ }^{\circ} \mathrm{C}$.

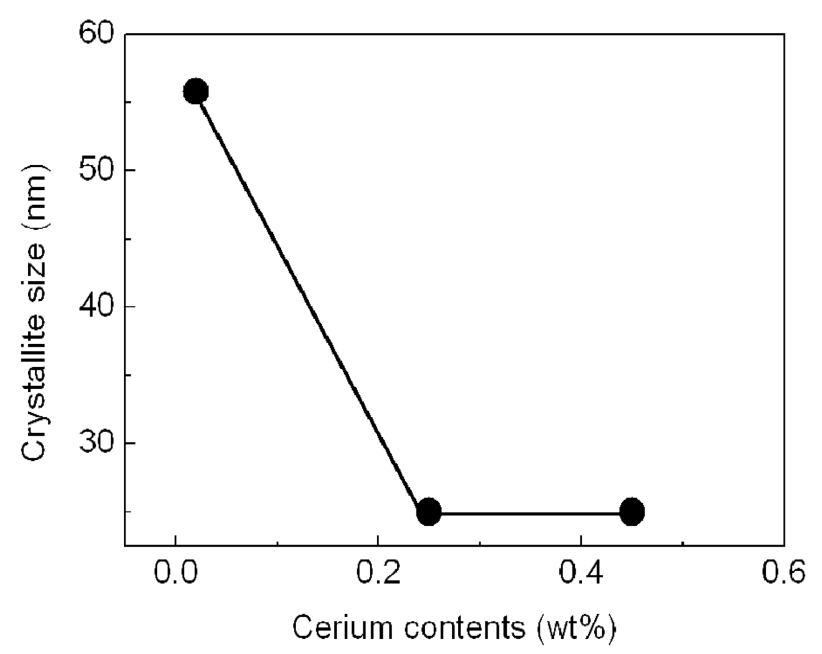

Fig. 2. Crystallite size of $\mathrm{TiO}_{2}$ powder with cerium contents calcined at $550{ }^{\circ} \mathrm{C}$.

pure $\mathrm{TiO}_{2}{ }^{17)}$ The high stability of anatase phase can be attributed to the formation and interaction of Ti-O-Ce bonds by inhibiting the transition of anatase phase, additionally inhibiting the growth of crystal grains. Moreover, rare earth ions have been used by other groups as stabilizing agents of materials especially mesoporous $\mathrm{TiO}_{2}{ }^{18)}$

The size of the crystallites of the cerium doped $\mathrm{TiO}_{2}$ powders were determined from the broadening of corresponding X-ray diffraction peaks by using Debye-scherrer's formula on the anatase (101) diffraction peaks,

$$
\mathrm{D}=(\kappa \lambda) / \beta \cos \theta,
$$

Where $\mathrm{D}$ is the average crystallite size, $\lambda$ is the wavelength of the $\mathrm{x}$-ray radiation, $\mathrm{k}$ is the scherrer's constant $(\kappa=0.9) . \beta$ is $\mathrm{x}$-ray diffraction peak and $\theta$ is the fullwidth at half maximum(FWHM). ${ }^{2,10)}$ 
The crystallite size of $\mathrm{Ce}-\mathrm{TiO}_{2}$ are shown in Fig. 2. It was found that the crystallite size of the obtained anatase particles decreased from $55 \mathrm{~nm}$ to $25 \mathrm{~nm}$ and the particle size decreased with increasing cerium contents.

DTA curves in Fig. 3 show a small endothermic peak below $100{ }^{\circ} \mathrm{C}$, which is attributed to desorption of water. Some other small peaks appear at $120^{\circ} \mathrm{C}$ and $225^{\circ} \mathrm{C}$, which are ascribed to the combustion decomposition of organic matters. A sharp endothermic reaction peak appeared between $250{ }^{\circ} \mathrm{C}$ and $359^{\circ} \mathrm{C}$, indicating a phase change of the powder from amorphous to anatase phase. It was noted that as the cerium content was increased, the crystallization temperature decreased. Fig. 4 shows a three-step weight loss pattern for $\mathrm{Ce}-\mathrm{TiO}_{2}$ powders. All powders show first weight loss at temperatures below $100{ }^{\circ} \mathrm{C}$, indicating that water started to evaporate from the powders. The next loss at temperatures between 120 ${ }^{\circ} \mathrm{C}$ and $350{ }^{\circ} \mathrm{C}$ can be attributed to the removal of chemisorbed water and the release of organic residues. The last weight loss from $380{ }^{\circ} \mathrm{C}$ to $600{ }^{\circ} \mathrm{C}$ is due to the removal of $-\mathrm{OH}$ groups. The wide range of temperature is associated with terminal Ti-OH and bridge Ti-OH-Ti. This is because dissociation temperature of these surface

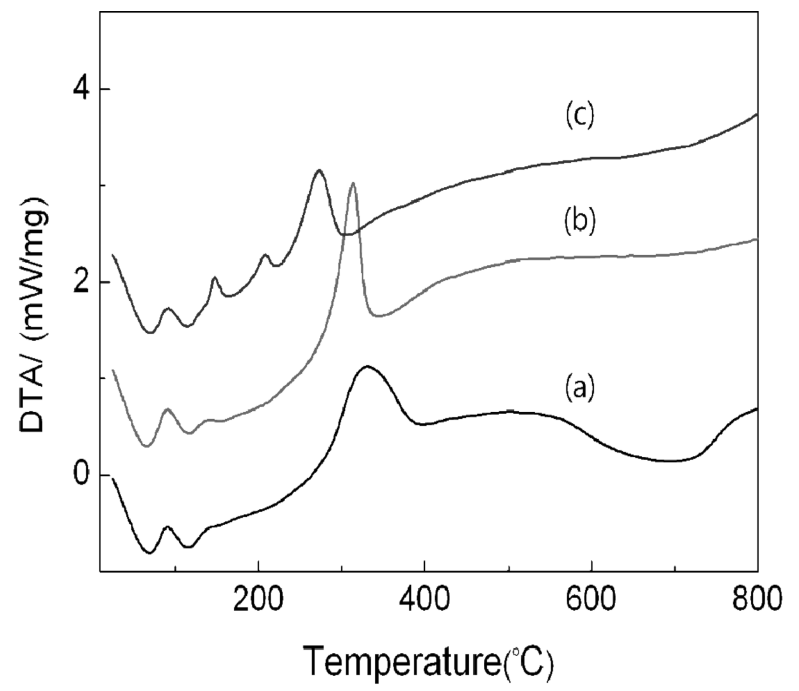

Fig. 3. DTA curves of (a) $\mathrm{TiO}_{2}$, (b) $0.09 \mathrm{wt} \% \mathrm{Ce}-\mathrm{TiO}_{2}$, and (c) $0.44 \mathrm{wt} \% \mathrm{Ce}-\mathrm{TiO}_{2}$ powders synthesized by sol-gel process.

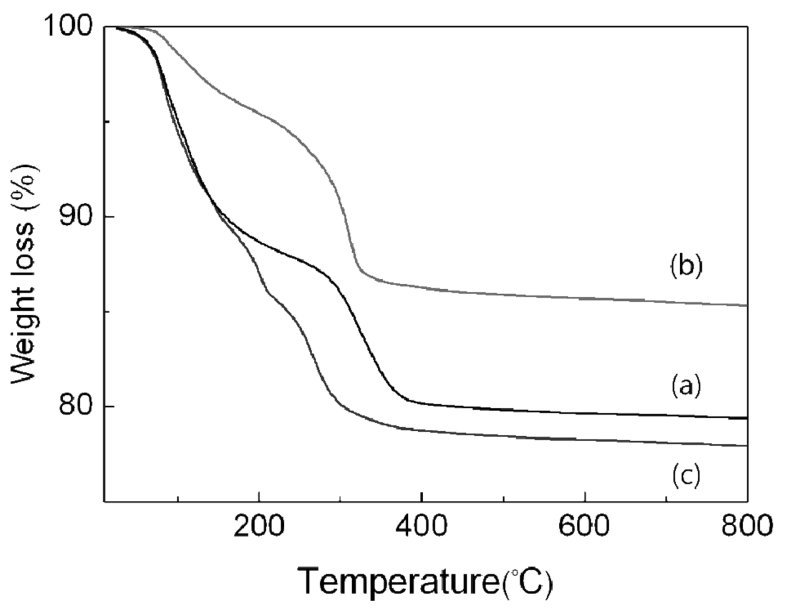

Fig. 4. TGA curves of (a) $\mathrm{TiO}_{2}$, (b) $0.09 \mathrm{wt} \% \mathrm{Ce}-\mathrm{TiO}_{2}$, and (c) $0.44 \mathrm{wt} \% \mathrm{Ce}-\mathrm{TiO}_{2}$ powders synthesized by sol-gel process.

-OH groups differs from each other depending upon the chemical surroundings. The last weight loss and a sharp exothermic peak are observed at about $300{ }^{\circ} \mathrm{C}$ in all sample and correspond to the crystallization of $\mathrm{TiO}_{2}$ phase. Total weight loss is approximately $20 \%$.

The FE-SEM images of $\mathrm{TiO}_{2}$ and $\mathrm{Ce}-\mathrm{TiO}_{2}$ powder shown in Fig. 5(and Fig. 6), illustrate that the addition of cerium led to a change in the morphology and spherical clusters of agglomerate structures were observed. The particle size decreases with increasing cerium contents. Yan et $\mathrm{al}^{19)}$, doping $\mathrm{CeO}$ into $\mathrm{TiO}_{2}$ not only suppressed the crystal growth of $\mathrm{TiO}_{2}$ but also prevented phase transition of anatase to rutle. Also, this can be attributed to the presence of Ce-O-Ti bonds. ${ }^{11)}$ The morphology of $\mathrm{TiO}_{2}$ and $\mathrm{Ce}-\mathrm{TiO}_{2}$ powders were consistent with the calculated crystallite size of XRD result.

The UV-vis spectra of pure $\mathrm{TiO}_{2}$ and $\mathrm{Ce}-\mathrm{TiO}_{2}$ powder shown in Fig. 7. There is a strong absorption at $200 \mathrm{~nm}$ up to $380 \mathrm{~nm}$ for pure $\mathrm{TiO}_{2}$ powder which can be attributed to the band gap excitation of anatase $(3.2 \mathrm{eV}) .^{2)}$ However, $\mathrm{Ce}-\mathrm{TiO}_{2}$ powder show absorption shifts towards longer wavelengths, thus extending absorption into the visible range. ${ }^{10,17)}$ Yan et $\mathrm{al}^{19)}$ suggested that photon penetration into $\mathrm{TiO}_{2}$ particles is a more likely explanation for the observed dependence of the optical absorption property

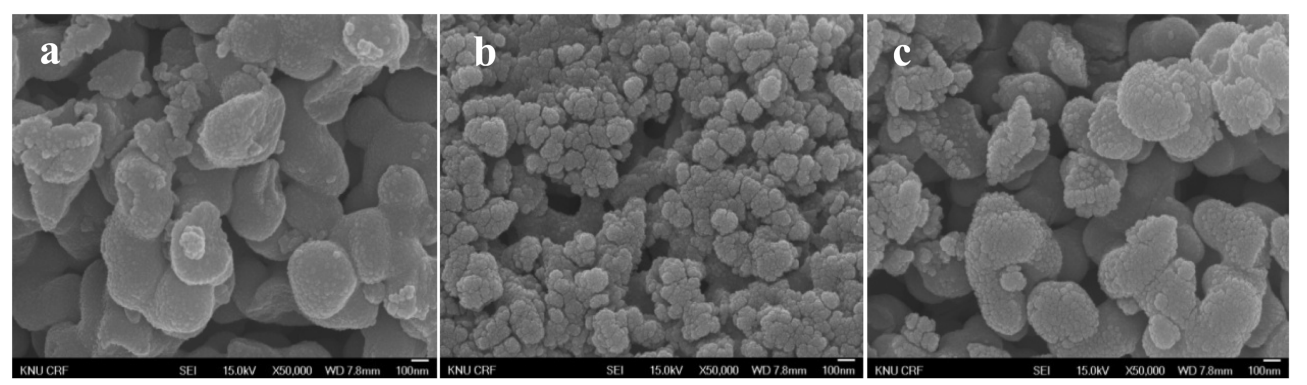

Fig. 5. FE-SEM micrographs of (a) $\mathrm{TiO}_{2}$, (b) $0.09 \mathrm{wt} \% \mathrm{Ce}-\mathrm{TiO}_{2}$, and (c) $0.44 \mathrm{wt} \% \mathrm{Ce}-\mathrm{TiO}_{2}$ powder calcined at $550{ }^{\circ} \mathrm{C}$. 


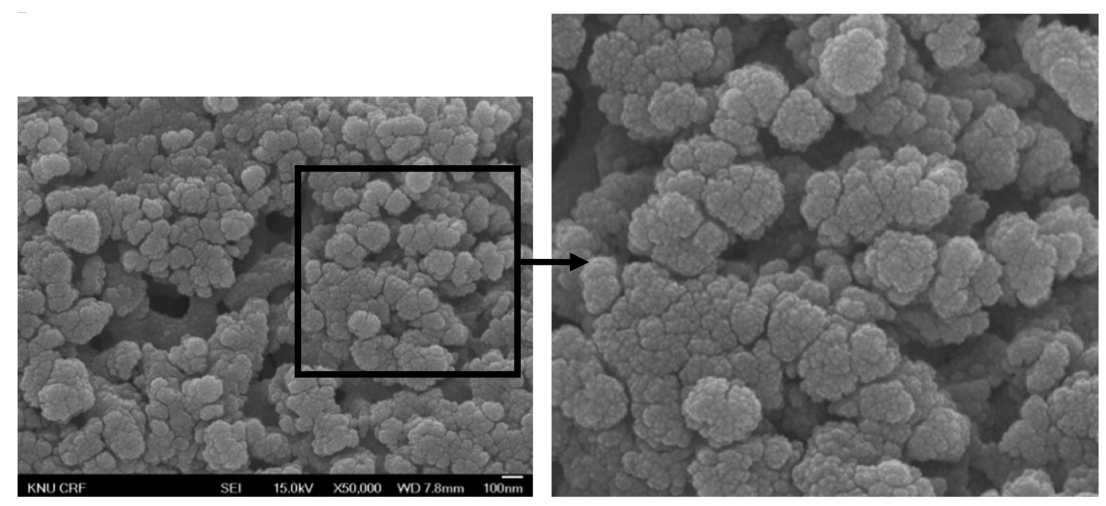

Fig. 6. Agglomeration of $\mathrm{Ce}-\mathrm{TiO}_{2}$ particles calcined at $550{ }^{\circ} \mathrm{C}$.

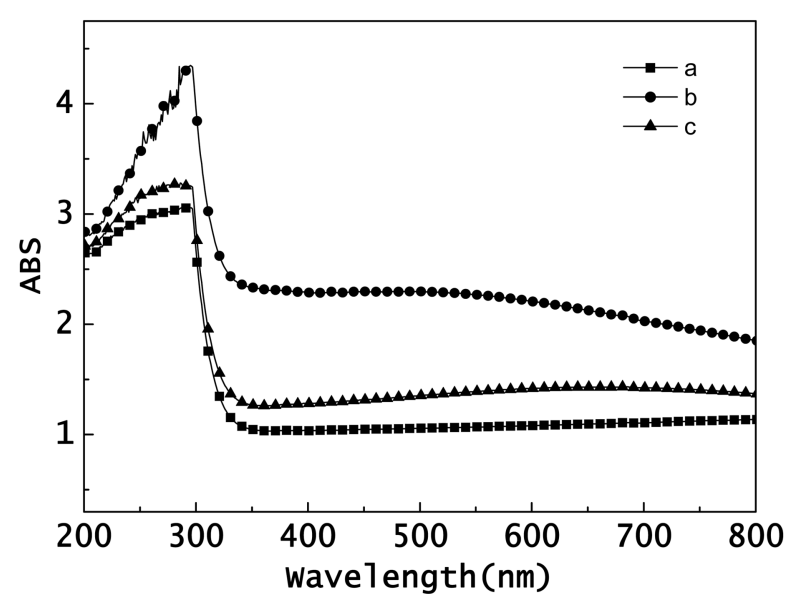

Fig. 7. UV/Vis spectra of (a) $\mathrm{TiO}_{2}$, (b) $0.09 \mathrm{wt} \% \mathrm{Ce}-\mathrm{TiO}_{2}$, and (c) 0.44 wt $\% \mathrm{Ce}-\mathrm{TiO}_{2}$ powder calcined at $550{ }^{\circ} \mathrm{C}$.

on the dopant content.

\section{Conclusion}

The preparation of $\mathrm{TiO}_{2}$ and $\mathrm{Ce}-\mathrm{TiO}_{2}$ powder by solgel process was systematically investigated. This study have shown that anatase type of $\mathrm{TiO}_{2}$ was obtained in as prepared $\mathrm{TiO}_{2}$ and $\mathrm{Ce}-\mathrm{TiO}_{2}$ powder. The addition of cerium into $\mathrm{TiO}_{2}$ leads to the reduction of crystallite size, which may be ascribed to the segregation of the dopant cations at the grain bondary, and preventing the growth of crystals and also this is explained by possible monolayer coverage of ceria over $\mathrm{TiO}_{2}$. The crystallization temperature decreased with increasing cerium contents. The crystallite size of $\mathrm{TiO}_{2}$ particles decreased from $55 \mathrm{~nm}$ to $25 \mathrm{~nm}$ and the particle size decreased with increasing cerium contents. Futhermore cerium doped $\mathrm{TiO}_{2}$ exhibit obviously enhanced absorbance in the visible light region compared to undoped $\mathrm{TiO}_{2}$.

\section{References}

1. U. G. Akpan, B. H. Hameed, J. Hazar. Mat., 170, 520 (2009).

2. C. H. Wei, X. H. Tang, J. R. Liang, S. Y. Tang, J. Environ. Sci., 19(1), 90 (2007).

3. U. G. Akpan, B. H. Hameed, Applied catalysis A: General, 375(1), 1 (2010).

4. A. W. Xu, Y. Gao, and H. Q. Liu,J. Catalysis, 207(2), 151 (2002).

5. A. Fujishima, T. N. Rao, D. A. Tryk, J. Photochem. Photobiol. C, photochem. Rev., 1(1), 1 (2000).

6. Q. Yuan, H. H. Duan, L. L. Li, L. D. Sun, Y. W. Zhang, C. H. Yan, J. Colloid and Inter. Sci., 335(2), 151 (2009).

7. D.Y. Shin, K.N. Kim, J. Kor. Ceram. Soc., 45(6), 345 (2008).

8. J. J. Zhu, J. Xie, M. Chen, D. Jiang, D. Wu, Colloids and Surfaces A: Physiochem. Eng. Aspects, 335, 178 (2010).

9. I. E. Grey, N. C. Wilson, J. Solid State Chem., 180(2), 670 (2007).

10. T. Tong, J. Zhang, B. Tian, F. Chen, D. He, M. Anpo, J. Colloid and Inter. Sci., 315(1), 382 (2007).

11. N. Hafizah, I. Sopyan, Inter. J. Photoenergy, 2009, 1 (2009).

12. G. Li, C. Liu, Y. Liu, App. Sur. Sci., 253, 2481 (2006).

13. A. Fujishima, X. Zhang, D. A. Tryk, Sur. Sci. Reports, 63, 515 (2008).

14. D. Y. Shin, K. N. Kim, Mat. Sci. Forum, 622, 679 (2009).

15. D. Y. Shin, G. Cao, K. N. Kim, Current Applied Physics, 11, 309 (2011).

16. E. M. Ndinda, Master thesis (in Korea), Kangwon Uni., (2011).

17. Adrian M. T. Silva, Claudia G. Silva, Goran Drazic, Joaquim L. Faria, Catalysis Today, 144(1-2), 13 (2009).

18. Y. H. Xu, Z. X. Zeng, J. Molecular Catalysis A: Chem., 279(1), 77 (2008).

19. Q. Z. Yan, X. T. Su, Z. Y. Huang, C. C. Ge, J. Euro. Ceram. Soc., 26(6), 915 (2006). 